\title{
Aneurysm Sac Size as a Predictor for Endoleak after Endovascular Aortic Aneurysm Repair of Stanford B Dissecting Thoracic Aortic Aneurysm: Role of MDCT Angiography
}

\author{
AMR A.H. GADALLA, M.D.*; HUSSEIN O. ELWAN, M.D.** and MOHAMED F. OSMAN, M.D.* \\ The Departments of Diagnostic \& Interventional Radiology* and Vascular Surgery**, Faculty of Medicine, Cairo University
}

\begin{abstract}
Background: The endovascular techniques for repair of thoracic aortic aneurysms are significantly increased nowadays, so the possibility of endoleak is also raised.

Aim of Work: Pre-operative evaluation of the aortic aneurysm using the sac size as a predictor for endoleak after endovascular repair of the thoracic Stanford B dissecting aortic aneurysms.

Methods: The study was carried over one hundred and seven patients (88 males and 19 females, range 50-75 year old) from October 2016 to November 2017. Pre and post operative evaluation of all examined patients was done using Multislice CT angiography. Types of endoleak were documented as well as the detailed assessment of the rest of the vascular tree was also done.

Results: Receiver Operating Characteristics (ROC) curve analysis was performed for aneurysm sac size, area under the curve (AUC) was nearly optimal 0.938 (95\% CI 0.891-0.984). The most suitable cut off point for aneurysm sac size was more than or equal to $6.2 \mathrm{~cm}$ with sensitivity $83.9 \%$ and specificity $85.5 \%$.
\end{abstract}

Conclusion: Based on our results, aneurysmal sac size combined with patient's age can be used as predictors for post interventional endoleak.

Key Words: EVAR-endoleak - CT angiography - Aneurysm - Sac size.

\section{Introduction}

ANEURYSM means that the vessel diameter exceeds 1.5 times its regular size. The risk of aortic aneurysm increases with age, smoking and hypertension. Rupture of an aortic aneurysm is often life threatening condition. The aneurysm should be repaired when the maximum diameter exceeds

Correspondence to: Dr. Amr A.H. Gadalla,

The Departments of Diagnostic \& Interventional Radiology, Faculty of Medicine, Cairo University
$5 \mathrm{~cm}$ or with annual expansion over1 $\mathrm{cm}$ [1] . Aortic dissection is common acute aortic abnormality with an incidence up to $0.2-0.8 \%$, so rapid and accurate diagnosis is important. Aortic dissection is caused by an intimal tear with blood entering the weakened vessel wall and subsequent proximal and distal extension in the media. Stanford and DeBakey are the two most common classification systems, depending on the site of the intimal tear and the extension. Because the Stanford system reflects the treatment approach, it became the most accepted classification system [2]. The Stanford system classifies aortic dissection into A and B types. Type A involves the ascending aorta with or without descending aorta involvement and surgical intervention is required for management while type B affects only the descending aorta and generally requires conservative medical treatment. Endovascular aortic aneurysm repair (EVAR) is less invasive procedure with no significant blood loss ,shorter recovery time and frequently used with lower mortality and high success rate ranging from $83-95 \%$ than open repair. Metallic stent covered with a synthetic fabric material is placed in the patent lumen of the aneurysm. This procedure occludes at the proximal and distal ends with subsequent total exclusion the aneurysm from normal arterial tree [3]. Proper pre-interventional assessment is mandatory to reduce the risk of complications [4]. Recently the frequency of complications from these procedures has increased due to high use of endovascular techniques. Endoleak is one of the most common complications of EVAR; it means contrast leakage into an excluded aneurysm sac after stent-graft placement. A classification system has established for endoleak and determines the urgency of intervention depending on endoleak type and site [я. In general, high-pressure endoleak 
(types I and III) require immediate management because of the relatively high risk of sac rupture while low-pressure endoleak (types II and V) are considered less urgent but may warrant eventual endovascular evaluation if there is progressive increase of sac size [6].

\section{Patients and Methods}

The study was carried over one hundred and seven (107) patients (88 males and 19 females, range 50-75 year old) from October 2016 to November 2017. The patients were referred from Kasr Al-Ainy vascular surgery clinics. Pre and postoperative evaluation of all examined patients with type B dissecting aortic aneurysm were included in the study after obtaining informed consent. The study is IBR approved.

\section{Exclusion criteria:}

- Patients refusing participation in the study.

- Patients with high renal functions or allergy to contrast media.

- Patients with other complications rather than endoleak.

The study was performed on Philips iCT 256 multislice scanners.

\section{CT Angiographic technique:}

- Non contrast images: Are obtained to evaluate the degree of wall calcifications and detection of intramural hematoma.

- CT angiography: Is then performed with thin sections and precise contrast timing from the lower neck to the symphysis pubis. The standardized dose of $100 \mathrm{~mL}$ nonionic contrast medium injected at rate of $4-5 \mathrm{~mL} / \mathrm{s}$ with bolus tracking at $150 \mathrm{HU}$. We use thin 1-mm axial images for primary review at the workstation. Several advanced reconstruction techniques should be used to assure accurate measurements, including 2D multiplanar reformatting, maximum intensity projection, curved planar reformatting, and $3 \mathrm{D}$ reconstruction.

\section{CT angiography images analysis:}

I- Pre-operative assessment:

- The radiologist should report the diameter of the aneurysmal sac and its extension as well as the length of aneurysmal neck. The presence or abcence of mural thrombosis.

- The site and extension of the dissecting intimal flap as well as identification of the false and true lumen should be documented.
II- Assessment of endoleak (Fig. 1):

- Type I endoleak: Leakage of blood between stent-graft and one of attachment sites.

- Type II endoleak: Reflux of blood into aneurysm sac through collateral vessels.

- Type III endoleak: Leakage of blood through defect in stent-graft wall.

- Type IV endoleak: Graft porosity, with leakage of blood through substance of stent-graft.

- V endoleak: Endotension.

\section{Statistical analysis:}

Pre-coded data was analyzed through the Statistical Package of Social Science Software program, version 23 (IBM SPSS Statistics for Windows, Version 23.0. Armonk, NY: IBM Corp.). Data was summarized as mean and standard deviation (SD) for quantitative variables and frequency and percentage for qualitative ones. Comparison between groups was performed using independent sample $t$-test and Mann Whitney test for quantitative variables and Chi square and Fisher's exact test for qualitative ones. Receiver Operating Characteristics (ROC) curve analysis was conducted to explore the predictive ability for Endoleak. $p$ values less than or equal to 0.05 were considered statistically significant.

\section{Results}

This study was prospectively carried on 107 patients (19 females and 88 males); the mean age for all patients was 57.8 years (age range, $45-75$ years). The mean for aneurysm sac size is $6 \pm 0.6$ SD (range, 5-7 .7). 76 patients (71\%) were free of endoleak and 31 (29\%) showed endoleak. Type I endoleak was seen in 11 patients and 20 patients presented with type II. According to the plan of management 20 patients were treated conservatively, where 11 patients treated by immediate intervention (Table 1 and Figs. 2,3).

Endoleak was significantly associated with older patients and larger aneurysm sac size (Table 2 ). There was no significant difference between type I and type II as regards age, sex and aneurysmal sac size (Table 3).

Receiver Operating Characteristics (ROC) curve analysis was performed for age and aneurysm sac size, area under the curve (AUC) for both was nearly optimal 0.985 (95\% CI $0.968-1.0)$ and 0.938 (95\% CI 0.891-0.984) respectively. The most suitable cut off age was more than or equal to 61years with sensitivity $93.5 \%$ and specificity $96.1 \%$, while the cut off point for aneurysm sac size was more than or equal to $6.2 \mathrm{~cm}$ with sensitivity $83.9 \%$. 


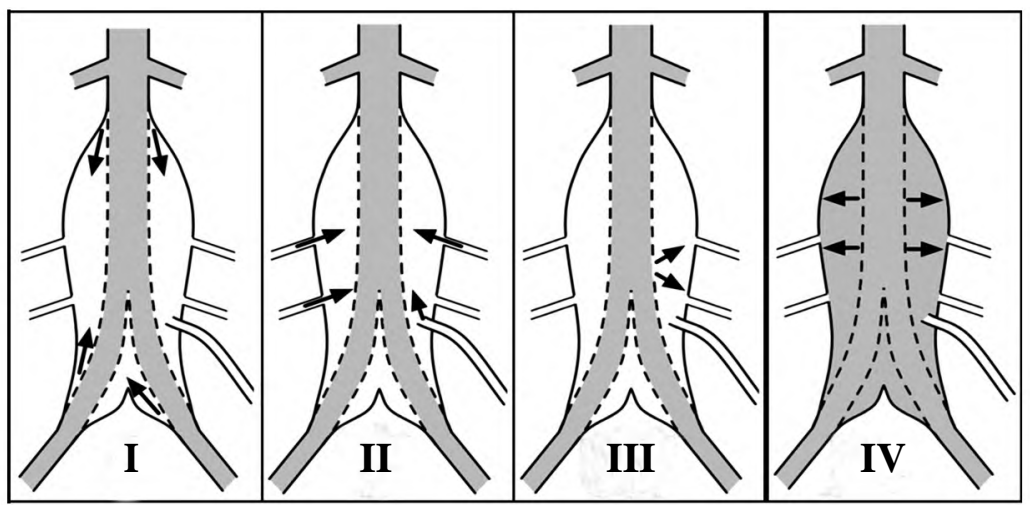

Fig. (1): Different types of endoleak [7]
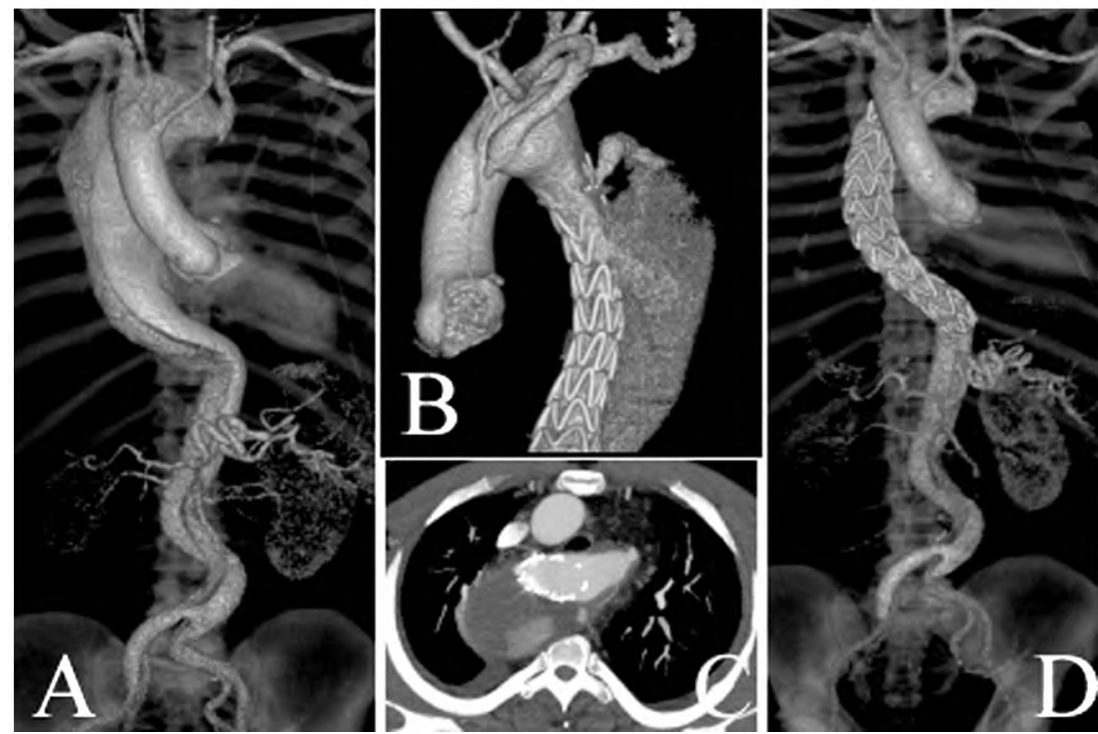

Fig. (2): 65 years old patient with right sided aortic arch with aneurysmal dilatation of descending thoracic aorta and Stanford type B dissection. (A-D) pre and post EVAR CTA images. A,B\&D VR images, C axial 2D image revealed pre EVAR Stanford B dissection (A), Type Ia endoleak 3 month after EVAR $(B \& C)$ and follow after 11 month revealed resolution of endoleak (D).
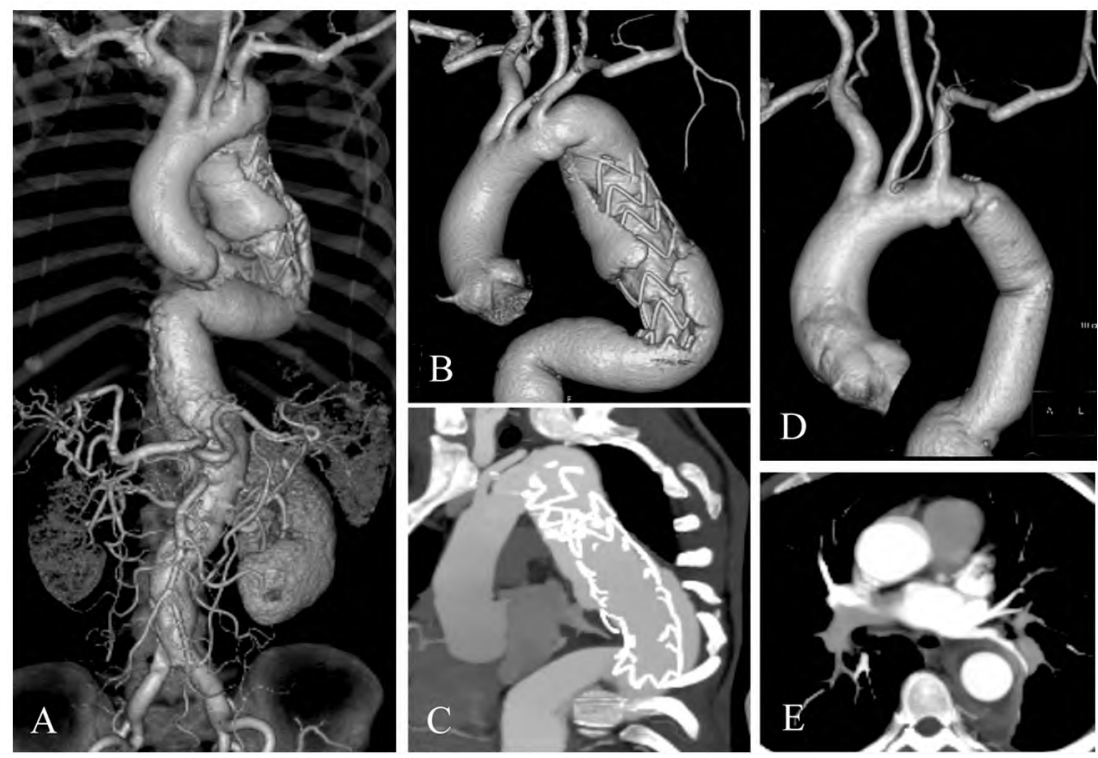

Fig. (3): 63 years old patient with aneurysmal dilatation of thoraco-abdominal aorta and Stanford type B dissection. (A-C) post EVAR CTA images. A\&BVR images, C sagittal MIP images revealed Type I endoleak 6 month after EVAR. Follow up 3 month after aortic grafting (D) VR \& (E) axial MIP images revealed normal appearance of the aortic graft. 


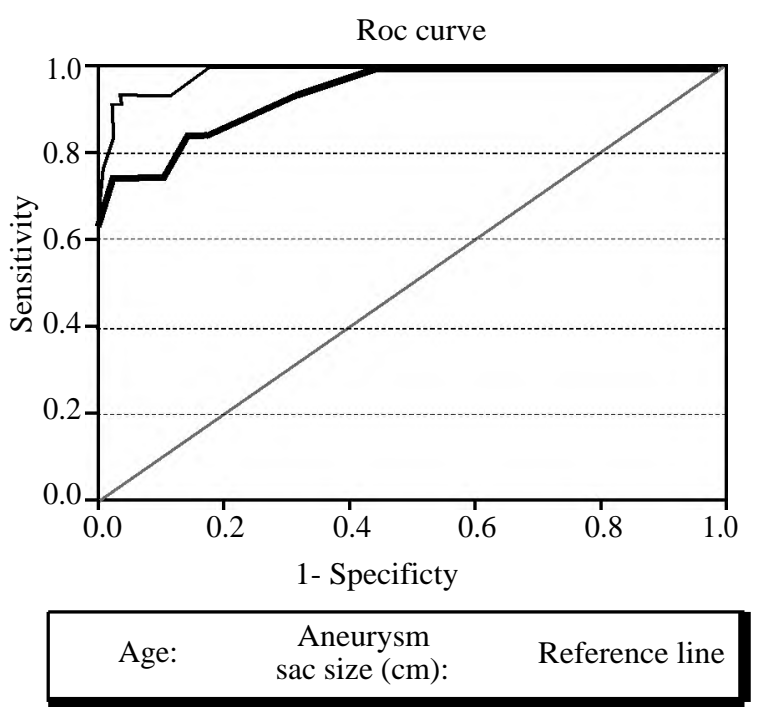

Fig. (4): ROC curve for both age and Aneurysm sac size to predict Endoleak

Table (1): Pre \&post-operative characteristics of the studied group.

\begin{tabular}{ll}
\hline & Description $(\mathrm{n}=107)$ \\
\hline Age: & \\
Range & $45-75$ \\
Mean \pm SD & $57.8 \pm 7.8$ \\
Sex: & \\
Male & $88(82.2 \%)$ \\
Female & $19(17.8 \%)$ \\
Aneurysm sac size $(\mathrm{cm}):$ & \\
Range & $5-7.7$ \\
Mean \pm SD & $6 \pm 0.6$ \\
Endoleak: & \\
$\quad+$ VE & $31(29 \%)$ \\
-VE & $76(71 \%)$ \\
Type of endoleak $(n=31):$ & \\
Type I & $11(35.5 \%)$ \\
Type II & $20(64.5 \%)$ \\
Treatment of endoleak $(n=31)$ & \\
Conservative & $20(64.5 \%)$ \\
Immediate intervention & $11(35.5 \%)$
\end{tabular}

Qualitative variables described as number (percentage), quantitative variables described as range, Mean \pm SD

Table (2): Pre-operative determinants of Aneurysm sac Endoleak.

\begin{tabular}{llll}
\hline & \multicolumn{2}{c}{ Endoleak } & \\
\cline { 2 - 3 } & \multicolumn{1}{c}{$\begin{array}{c}p- \\
(\mathrm{VE}=31)\end{array}$} & $\begin{array}{c}-\mathrm{VE} \\
(\mathrm{n}=76)\end{array}$ & \\
value \\
\hline Age: & & & \\
$\quad$ Range & $58-75$ & $45-65$ & $<0.001$ \\
$\quad$ Mean \pm SD & $67.7 \pm 4.7$ & $53.7 \pm 4.4$ & \\
Sex: & & & \\
$\quad$ Male & $26(83.9)$ & $62(81.6)$ & 0.778 \\
$\quad$ Female & $5(16.1)$ & $14(18.4)$ & \\
Aneurysm sac size $(\mathrm{cm}):$ & & & \\
$\quad$ Range & $5.8-7.7$ & $5-6.5$ & $<0.001$ \\
$\quad$ Mean \pm SD & $6.8 \pm 0.5$ & $5.7 \pm 0.4$ & \\
\hline
\end{tabular}

Table (3): Comparison between different types of Endoleak regarding preoperative characteristics.

\begin{tabular}{llll}
\hline & \multicolumn{2}{c}{ Type of endoleak } & \\
\cline { 2 - 3 } & \multicolumn{1}{c}{$\begin{array}{c}\text { Type I } \\
(\mathrm{n}=11)\end{array}$} & $\begin{array}{c}\text { Type II } \\
(\mathrm{n}=20)\end{array}$ & value \\
& & & \\
\hline Age: & $64-75$ & $58-75$ & 0.227 \\
$\quad$ Range & $69.4 \pm 4.1$ & $66.9 \pm 4.8$ & \\
$\quad$ Mean \pm SD & & & \\
$\begin{array}{l}\text { Sex: } \\
\quad \text { Male }\end{array}$ & $10(90.9)$ & $16(80)$ & 0.631 \\
$\quad$ Female & $1(9.1)$ & $4(20)$ & \\
Aneurysm sac size $(\mathrm{cm}):$ & & & \\
$\quad \begin{array}{l}\text { Range } \\
\quad \text { Mean } \pm \text { SD }\end{array}$ & $6-7.7$ & $5.8-7.7$ & 0.059 \\
\hline
\end{tabular}

\section{Discussion}

EVAR is widely used acceptable method replacing the open surgeries for aortic aneurysms treatment with less complications and mortality rate [8-10] . Proper imaging protocol should be done to ensure endoleak detection and to determine the endoleak type to guide the management plan [11] Multislice CT angiography is the most accurate imaging tool for proper assessment of dissecting thoracic aortic aneurysm due to the high spatial and contrast resolution providing detailed assessment of the vascular tree and accurate delineation of the aneurysm size after reconstruction of axial sections producing $2 \mathrm{D}$ and $3 \mathrm{D}$ multiplanar reformatted images with more accurate and sensitive endoleak detection than conventional angiography $[12,13]$

Veith et al., [15] reported that endoleak can occur in up to $20-25 \%$ of patients after endovascular repair. Our study recorded that 76 patients $(71 \%)$ were free of endoleak and 31 (29\%) showed endoleak. The incidence of endoleak is considered relatively higher than the forementioned study possibly due to older age of patient and relative large sizes of dissecting aneurysms however no significant difference between type I and type II as regards age, sex and aneurysmal sac size. We also found that the most suitable cut off age was more than or equal to 61years with sensitivity $93.5 \%$ and specificity $96.1 \%$, while the cut off point for aneurysm sac size was more than or equal to $6.2 \mathrm{~cm}$ with sensitivity $83.9 \%$ and specificity $85.5 \%$. The results agreed with the study also done by Kassem [16] that reported 14 cases of endoleak out of 37 ( 22 males and 15 females) examined cases with an incidence of $37.8 \%$. Patients included in the study (range, 59-73 years \& average 66 years). The higher incidence of endoleak was also 
referred to the larger sac sizes and older age. The study done by Hong et al., [17] reported that 9 cases of type I endoleak out of 50 examined cases were diagnosed (18\%). 5 cases showed endoleak at proximal end of graft, 3 cases at distal end and 1 case at junctional attachment site. In our study, we reported that Type I endoleak was seen in 11patients and 20 patients presented with type II out of 31 positive cases. Rhee et al., [18] reported that type I and type III endoleak require immediate interference due to high pressure and risk of aneurysm sac rupture. Tolia et al., [19] reported that type II endoleak represents at least $40 \%$ of endoleak. This differs from our results as type II endoleak was seen in 20 cases $(65.5 \%)$ out of 31 positive cases matched to study performed by Hong et al., [7] as they reported 32 type II endoleak out of 50 cases (64\%). Type II endoleak usually put under observation and follow up which would often regress or resolute without therapy [20] . In our study 20 cases were treated conservatively while 11 cases were treated by immediate intervention. Type IV endoleak is usually self-limiting, however type $\mathrm{V}$ endoleak is low-risk lesions but progressive increase of the aneurysm sac usually requires further intervention [21].

\section{Conclusion:}

Endoleak detection requires detailed and cautious assessment by multislice CT angiography. Based on our results, aneurysm sac size combined with patient's age can be used as predictors for post interventional endoleak.

\section{References}

1- B REWS TER D.C., CRONENWETT J.L., HALLETT J.W., JOHNSTON K.W., KRUPSKI W.C. and MATSUMURA J.S.: Joint Council of the American Association for Vascular Surgery and Society for Vascular Surgery. Guidelines for the treatment of aortic aneurysms: report of a subcommittee of the Joint Council of the American Association for Vascular Surgery and Society for Vascular Surgery. J. Vasc. Surg., 37: 1106-1117, 2003.

2- SHIGA T., WAJIMA Z., APFEL C.C., INOUE T. and OHE Y.: Diagnostic accuracy of transesophageal echocardiography, helical computed tomography, and magnetic resonance imaging for suspected thoracic aortic dissection: systematic review and meta-analysis. Arch. Intern. Med., 166: 1350 -1356, 2006.

3- RIDDELL J.M., BLACK J.H., BREWSTER D.C. and DUNN P.F.: Endovascular aortic aneurysm repair. Int. Anesthesiol. Clin., 43: 79-91, 2005.

4- ABBRUZZESE T.A., KWOLEK C.J., BREWSTER D.C., et al.: Outcomes following endovascular abdominal aortic aneurysm repair (EVAR): An anatomic and device-specific analysis. J. Vasc. Surg., 48: 19-28
5- AGGARWAL S., QAMAR A., SHARMA V. and SHARMA A.: Abdominal aortic aneurysm: A comprehensive review. Exp. Clin. Cardiol., 16:11-15, 2011.

6- STAVROPOULOS S.W. and CHARAGUNDLA S.R.: Imaging techniques for detection and management of endoleaks after endovascular aortic aneurysm repair. Radiology, 243: 641-655, 2007.

7- ABBRUZZESE T.A., KWOLEK C.J., BREWSTER D.C., et al.: Outcomes following endovascular abdominal aortic aneurysm repair (EVAR): An anatomic and device-specific analysis. J. Vasc. Surg. 48: 19-28, 2008.

8- KAJIWARA K., YAMAGAMI T., URASHIMA M., TOMIYOSHI H., KAKIZAWA H., et al.: Embolization for type 2 endoleak with sac expansion after endovascular repair of aortic aneurysm: Safety and effectiveness Springer Plus, 5: p. 262, 10.1186/s40064-016-1934-x, 2016.

9- MALAS M., ARHUIDESE I., QAZI U., et al.: Perioperative mortality following repair of aortic aneurysms: application of a randomized clinical trial to real-world practice using a validated nationwide data set JAMA Surg., 149: pp. 1260-1265, 2014.

10- SPEICHER P., BARBAS A. and MUREEBE L.: Open versus endovascular repair of ruptured aortic aneurysms Ann. Vasc. Surg., 28: p. 1239, 2014.

11- GANDHI R., BRYCE Y., GANGULI S., et al.: Management of Type II Endoleaks. Available options for treating the most common type of endoleak after EVAR. Endovascular Today. April., vol. 15 (4): 42-48, 2016.

12- Parmer S.S., Carpenter J.P., Stavropoulos S.W., et al.: Endoleaks after endovascular repair of thoracic aortic aneurysms J. Vasc. Surg., 44: pp. 447-452, 2006.

13- ARMERDING M., RUBIN G.D., BEAULIEU C.F., et al.: Aortic aneurysmal disease: Assessment of stent-graft treatment-CT versus conventional angiography Radiology, 215: pp. 138-146, 2000.

14- STAVROPOULOS S.W. and CHARAGUNDLA S.R.: Imaging techniques for detection and management of endoleaks after endovascular aortic aneurysm repair. Radiology, 243 (3): pp. 641-655, 10.1148/radiol.2433 051649, 2007.

15- VEITH F.J., BAUM R.A., OHKI T., et al.: Nature and significance of endoleaks and endotension: Summary of opinions expressed at an international conference J. Vasc. Surg., 35: pp. 1029-1035, 2002.

16- TAMER W. KASSEM.: Follow-up CT angiography post EVAR: Endoleaks detection, classification and management planning. The Egyptian Journal of Radiology and Nuclear Medicine Volume 48, Issue 3, September Pages 621-626, 2017.

17- HONG C., HEIKEN J.P., SICARD G.A., et al.: Clinical significance of endoleak detected on follow-up CT after endovascular repair of abdominal aortic aneurysm AJR Am. J. Roentgenol, 191 (3): pp. 808 813, 10.2214/AJR. 07.3668, 2008.

18- RHEE S.J., OHKI T., VEITH F.J. and KURVERS H.: Current status of management of type II endoleaks after endovascular repair of aortic aneurysms. Ann. Vasc. Surg., 17 (3): pp. 335-344, 2003 
19- TOLIA, R. LANDIS, P. LAMPARELLO, et al.:Type II endoleak after endovascular repair of aortic aneurysms: Natural history. Radiology, 235: pp. 683-686, 2005.

20- FUNAKI, N. BIROUTI, S.M. ZANGAN, T.G, NAVULURI, et al.: Evaluation and treatment of suspected type II endoleak in patients with enlarging aortic aneurysms
J. Vasc. Interv. Radiol., (JVIR), 23 (7): pp. 866-872, 2012

21- BASHIR M.R., FERRAL H., JACOBS C., et al.: Endoleak after endovascular aortic aneurysm repair: Management strategies according to CT findings. AJR. Am. J. Roentgenol., 192 (4): pp. W178-W186, 10.2214/AJR.08.1593, 2009

\section{حجم شريان الأورطى التمددى كمؤشر للتسريب الوعائى بعد إصلاح

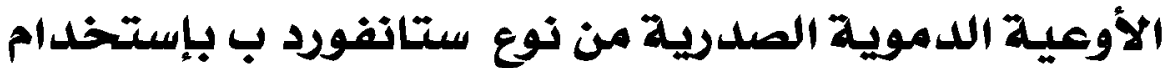 الأشعة المقطعية متعددة المقاطع}

نظراً لزيادة تقنيات الأوعية الدموية لتصليح تمدل شريان الأورطى الصدرى بشكل ملحوظ فى الوقت الحاضر ، مما أدى الى زيادة فرص حدوث التسريب الوعائى أيضاً.

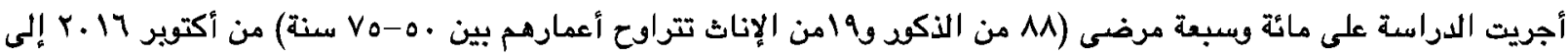

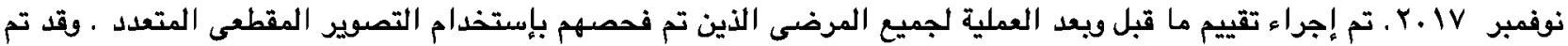
توثيق أنواع التسريب الوعائى. وكذ للك تم إجراء تقييم مفصل لبعلية لبع الأوعية الدموية أيضاً.

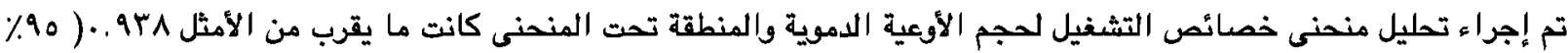

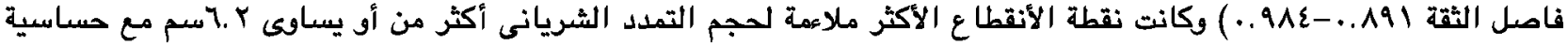

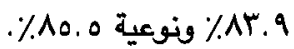

أستناداً إلى نتائجنا ، يمكن أستخدام حجم تمدد الأوعية الدموية جنباً الى جنب عمر المريض كمؤشر لإمكانية حدوث التسريب الشريانى. 